\title{
Earliest direct evidence of plant processing in prehistoric Saharan pottery
}

\author{
Julie Dunne ${ }^{1}$, Anna Maria Mercuri², Richard P. Evershed ${ }^{1 \star}$, Silvia Bruni ${ }^{3}$ and Savino di Lernia ${ }^{4,5}$
}

\begin{abstract}
The invention of thermally resistant ceramic cooking vessels around 15,000 years ago was a major advance in human diet and nutrition ${ }^{1-3}$, opening up new food groups and preparation techniques. Previous investigations of lipid biomarkers contained in food residues have routinely demonstrated the importance of prehistoric cooking pots for the processing of animal products across the world 4 . Remarkably, however, direct evidence for plant processing in prehistoric pottery has not been forthcoming, despite the potential to cook otherwise unpalatable or even toxic plants ${ }^{2,5}$. In North Africa, archaeobotanical evidence of charred and desiccated plant organs denotes Early Holocene hunter-gatherers routinely exploited a wide range of plant resources ${ }^{6}$. Here, we reveal the earliest direct evidence for plant processing in pottery globally, from the sites of Takarkori and Uan Afuda in the Libyan Sahara, dated to 8,200-6,400 calBC. Characteristic carbon number distributions and $\delta^{13} \mathrm{C}$ values for plant wax-derived $n$-alkanes and alkanoic acids indicate sustained and systematic processing of $\mathrm{C}_{3} / \mathrm{C}_{4}$ grasses and aquatic plants, gathered from the savannahs and lakes in the Early to Middle Holocene green Sahara.
\end{abstract}

Diet is a driving force in human evolution, linked with the development of physiology together with ecological, social, and cultural change within the hominin lineage $\mathrm{e}^{1-3}$. The processing of foodstuffs was a major innovation, with the cooking of plants a crucial step as this would have increased the availability of starch as an energy source and rendered otherwise toxic and/or inedible plants palatable and digestible $e^{2,5}$. The need for increased processing likely arose with the expansion in dietary plant diversity suggested by the increased complexity of plant palaeobotanical assemblages recovered from Pleistocene and Early Holocene hunter-gatherer sites across the world ${ }^{7}$. Specialization in particular plants, notably cereals and pulses, is regarded as one of the characteristics of the Neolithic domestic agricultural "package" in the Near East and Europe, although the sequence and nature of plant and animal domestication varied markedly geographically.

This is particularly manifest in North Africa where the early Holocene green Sahara ${ }^{8}$ comprised a mosaic of humid savannah with extensive herds of large fauna, interspersed with networks of rivers and lakes supporting aquatic plants and animals. The richness of the environment provided significant food procurement opportunities, initially for the semi-sedentary pottery-using hunter-gatherers of the region and then for the first pastoralists who exploited domesticated livestock, such as cattle, sheep and goats ${ }^{9}$.

North Africa is one of the two known centres worldwide for the invention of pottery (c. 10,000 calBC), with East Asia (c. 14,000 calBC) being the other ${ }^{10,11}$. Crucially, pottery from two well-dated Libyan Saharan archaeological sites allows the investigation of plant processing as a dietary strategy throughout this period. Uan 48 Afuda cave ${ }^{12}$ was occupied by hunter-gatherers during the period 49 $8,200-6,700 \mathrm{BC}$, and the Takarkori rock shelter is one of the few 50 Saharan sites which records the transition from hunter-gathering 51 $(8,200-6,400 \mathrm{BC})$ to food production $(6,400-3,000 \mathrm{BC})$, with nearly 5,000 years of human occupation ${ }^{13}$ (Supplementary information Figs 1-3; map of Tadrart Acacus Mountains, Libya; Uan Afuda cave and Takarkori rock shelter). Both sites yielded sedimentary deposits extraordinarily rich in pollen and plant macrofossils, suggesting exploitation for human consumption ${ }^{14,15}$. At Takarkori, these included exceptionally well-preserved organs from plants such as Typha, Ficus, Cupressus, Tragus, Cassia and Balanites aegyptica (Fig. 1) together with Panicoideae fruits (for example, 6 Echinochloa, Panicum and Setaria). Significantly, pottery was also 6 introduced around this time $\mathrm{e}^{10,11}$ presenting the unique possibility 6 to explore plant exploitation and processing among these Holocene 63 hunter-gatherer people through organic residues preserved in some 6 of the regions earliest cooking vessels.

A total of 110 potsherds from Early to Middle Holocene contexts 66 at Takarkori and Uan Afuda (Supplementary information Figs 467 and 5) were solvent extracted using established protocols and ana- 68 lysed using gas chromatography (GC), gas chromatography mass 69 spectrometry (GCMS) and gas chromatography combustion 70 isotope ratio mass spectrometry (GC-C-IRMS) ${ }^{4,9}$. Of the 81 sherds analysed from Takarkori, 29 displayed distributions typical of an animal fat origin ${ }^{9}$ and 38 displayed distributions strongly indicative of a plant origin (Late Acacus, $n=4$; Early Pastoral, $n=2$ and Middle Pastoral, $n=32$; Supplementary Tables 1 and 2) with the remainder likely to reflect either the processing of both plant and animal products in vessels or the multi-use of vessels. Potsherd samples from the Uan Afuda cave, Libya, all from Late Acacus stratigraphic contexts dated by multiple radiocarbon measures, totalled 29 , of which 22 yielded appreciable lipid concentrations (76\%). Of these, 18 of the total lipid extracts (TLEs) yielded lipid profiles indicative of a plant origin (82\%).

The lipid profiles from both sites are characterized by unusually complex mixtures of aliphatic compounds, including short-, 8 medium- and long-chain fatty acids, diacids, $\boldsymbol{\alpha}, \omega$-hydroxyacids and 8 $n$-alkanes (Fig. 2). The exceptional preservation of lipids in the 8 desert environment presented opportunities to use a range of diag- 87 nostic criteria and proxies to explore the nature of the lipid distributions in the pottery: palmitic/stearic acid ratios ( $\mathrm{P} / \mathrm{S}$ ratio), average chain length ${ }^{16}$ (ACL), carbon preference index ${ }^{17}$ (CPI), $P_{\text {aq }} 9$ proxy ratio ${ }^{18}$ and compound-specific $\delta^{13} \mathrm{C}$ values are summarized 9 in Table 1 (see also Supplementary Information Tables 1 and 2).

The saturated fatty acids seen in all gas chromatograms (Fig. 2a-c) 93 are common degradation products of acyl lipids. Fresh fatty acids of 94

'Organic Geochemistry Unit, School of Chemistry, University of Bristol, Cantock's Close, Bristol BS8 1TS, UK. '2aboratorio di Palinologia e Paleobotanica, Dipartimento di Scienze della Vita, Università degli Studi di Modena e Reggio Emilia, Viale Caduti in Guerra 127, 41121 Modena, Italy. ${ }^{3}$ Dipartimento di Chimica, Università degli Studi di Milano, Via C. Golgi 19, 20133 Milano, Italy. ${ }^{4}$ Dipartimento di Scienze dell'Antichità, Sapienza, Università di Roma, Via dei Volsci, 122 - 00185 Roma, Italy. ${ }^{5}$ School of Geography, Archaeology \& Environmental Sciences, University of the Witwatersrand, Johannesburg, Private Bag 3, Wits 2050, South Africa. *e-mail: r.p.evershed@bristol.ac.uk 


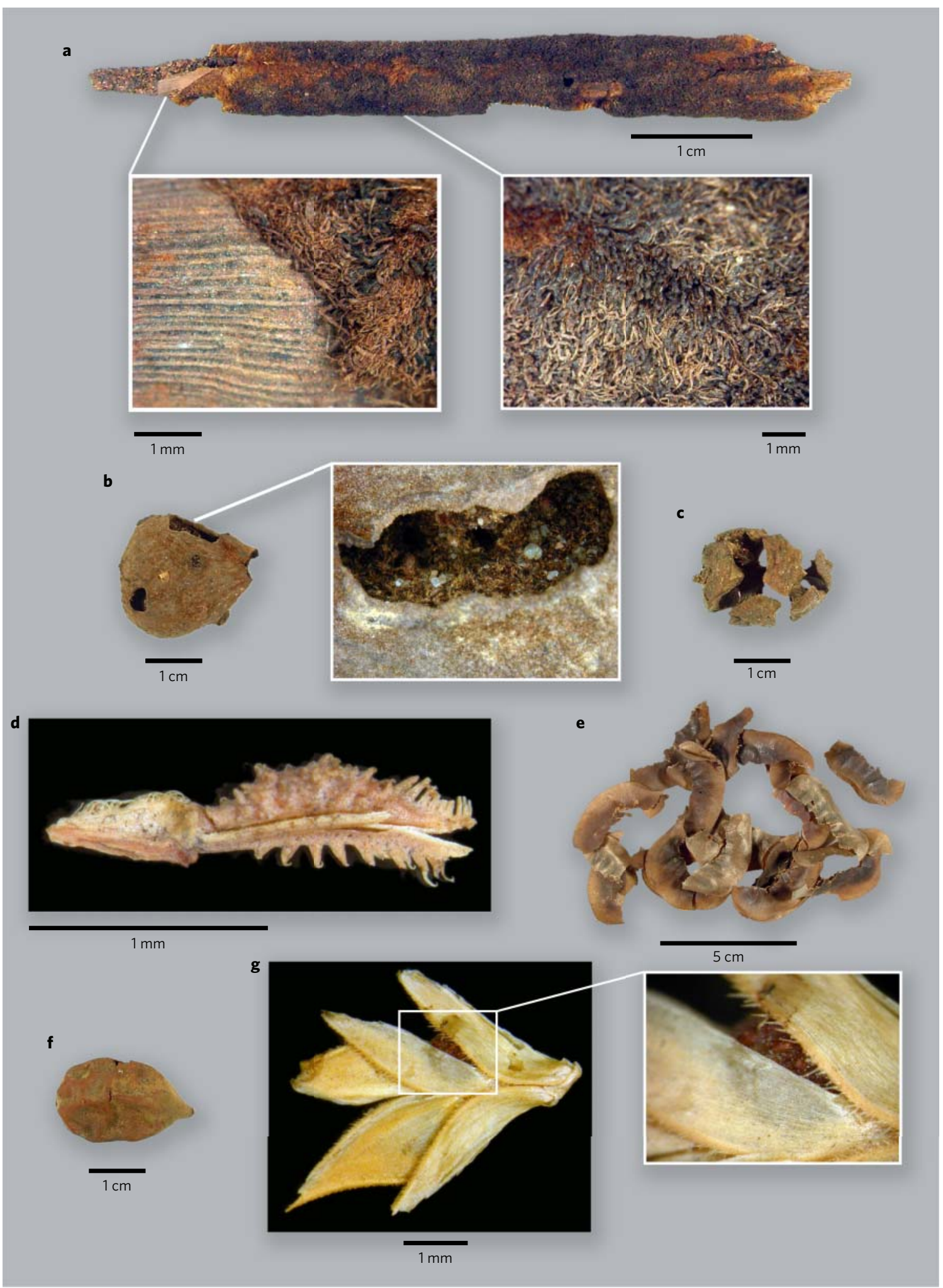

Figure 1 | Exceptionally preserved archaeobotanical remains from Takarkori rock shelter (Tadrart Acacus, SW Libya), dating approximately from c. 7,500 to 4,200 calBc. a, Inflorescence of Typha (Late Acacus 3 to c. 6,800 calBC). b, Syconium of Ficus sp., and details (Late Acacus 2 to c. 7,500 calBC). c, Galbulus of Cupressus (Middle Pastoral 2). d, spikelet of Tragus (Middle Pastoral 2 to c. 4,200 calBC). e, legumes of Cassia (Early Pastoral 1 to c. 6,350 calBC). f, Fruit of Balanites aegyptica (Late Acacus 3 to c. 6,800 calBC). g, Spikelet of Dactyloctenium aegyptium and details of grain (Middle Pastoral 2 to c. 4,200 calBc). (C The Archaeological Mission in the Sahara, Sapienza University of Rome).

1 plants are dominated by unsaturated components (such as $\mathrm{C}_{18: 1}$ and

$2 \mathrm{C}_{18: 2}$ ) but these are either absent or greatly reduced in abundance in 3 aged fats and oils because of oxidation. Well-known plant degradation products are evident in the gas chromatograms as 4 short-chain fatty acids, such as $n$-nonanoic acid and diacids, for 5 example azelaic acid. Strong evidence for plant lipids dominating 6 


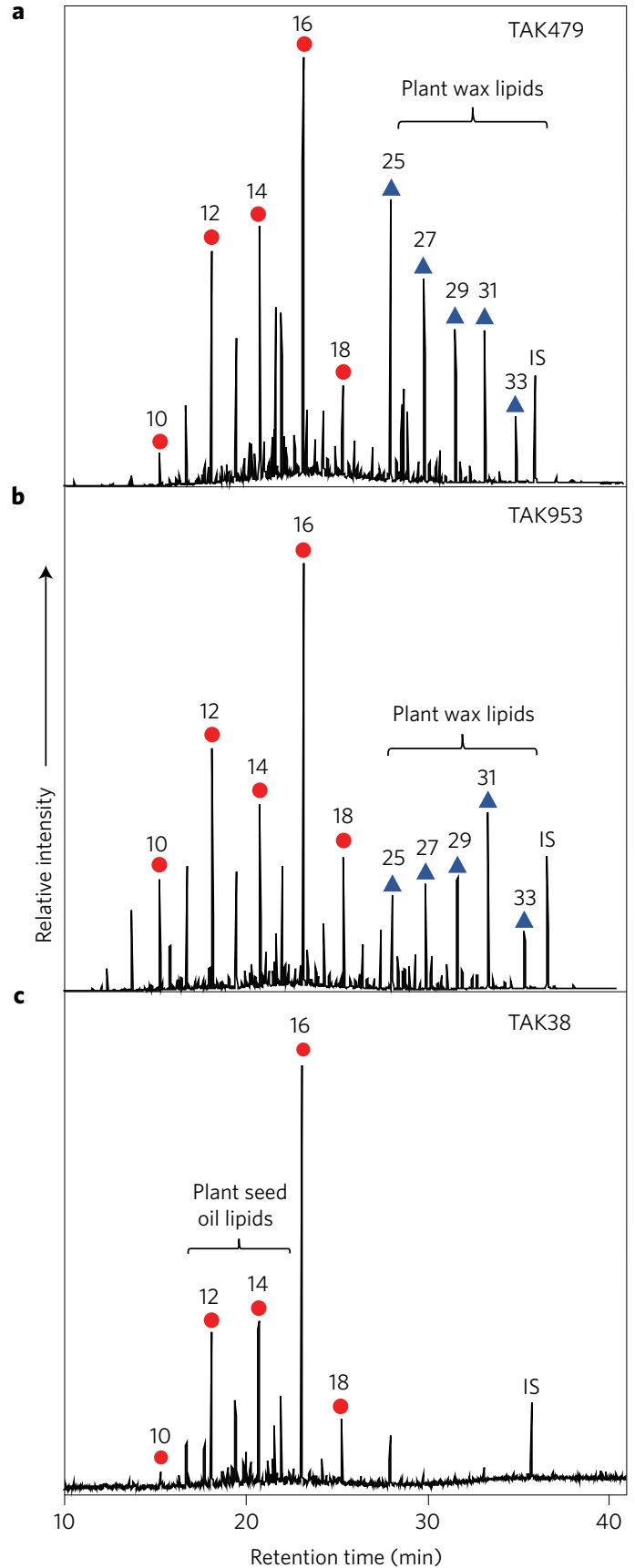

Figure 2 | Partial gas chromatograms of trimethylsilylated TLEs from potsherds excavated from Takarkori rock shelter. a-c, Chromatographic peak identities denoted by filled triangles comprise $n$-alkanes in the carbon change range $\mathrm{C}_{25: 0}-\mathrm{C}_{33: 0}$ and filled circles indicate straight-chain fatty acids in the carbon chain range $\mathrm{C}_{9: 0}-\mathrm{C}_{30: 0}$, maximizing at $\mathrm{C}_{16: 0}$. a-ce The distributions show leaf wax $n$-alkanes and plant fatty acids $n$-alkanes maximizing at $\mathrm{C}_{25}$ characteristic of an aquatic plant origin (a), n-alkanes maximizing at $\mathrm{C}_{31}$ originate from $\mathrm{C}_{3}$ or $\mathrm{C}_{4}$ wild grasses or lake-margin plants, such as sedges, (b) and plant fatty acid profile showing the predominance of the $\mathrm{C}_{16: 0}$ over the $\mathrm{C}_{18: 0}$ fatty acid and high abundance of $\mathrm{C}_{12: 0}$ and $\mathrm{C}_{14: 0}$ fatty acids, characteristic of plant seed oil lipids (c). IS, internal standard, $\mathrm{C}_{34}$ n-tetratriacontane.

1 the extracts comes from the high abundance of palmitic versus stearic acid expressed by high $\mathrm{P} / \mathrm{S}$ ratios $(>4)$, a pattern never seen in animal fats, especially those of archaeological origin ${ }^{19}$. The high abundance of lauric $\left(\mathrm{C}_{12: 0}\right)$ and myristic $\left(\mathrm{C}_{14: 0}\right)$ acids is very unusual as these compounds exist only at very low abundance in most plant lipids
(Fig. 2c). They occur in high abundance in palm kernel oil ${ }^{20-21}$ but 6 the date palm was not thought to have been present in the Sahara at that time, its natural range in prehistory being restricted to Southwest Asia. Seed oil chain lengths can range from 8 to 24 9 carbons, with degrees of unsaturation ranging from 0 to $4^{20-22} \cdot 10$ Likely candidates for seed oil processing in the vessels might be 11 both $\mathrm{C}_{3}$ and $\mathrm{C}_{4}$ wild grasses, ubiquitous in the archaeological deposits 12 at both sites. The high $\mathrm{P} / \mathrm{S}$ ratios of these residues also suggest that oil 13 was processed in the pots ${ }^{23}$, and, interestingly, some vessels with high 14 $\mathrm{P} / \mathrm{S}$ ratios do not include $n$-alkanes, denoting the presence of plant 15 waxes, suggesting the dedicated processing of plant fruits and seeds 16 rather than leafy plants or stems.

However, the presence of long-chain fatty acids up to $\mathrm{C}_{30}$ is 18 strongly indicative of origin in leaf or stem epicuticular waxes, 19 although such compounds are also found in suberin ${ }^{24}$, an aliphatic 20 polyester found in all plants. Overall, the different distributions of 21 fatty acids points to extensive processing of a range of different 22 plant types and organs, such as grains/seeds and leafy plants and 23 stems, in the pottery.

The abundant $n$-alkanes also derive from plant epicuticular 25 waxes, with two main signatures dominating the extracts: either 26 medium chain length $n$-alkanes, $\mathrm{C}_{25}$ or $\mathrm{C}_{27}$, or longer chain 27 $n$-alkanes, namely the $\mathrm{C}_{31} n$-alkane (Fig. 2a,b). Comparison with 28 the archaeobotanical record from the sites, and known affiliations, 29 suggests the lipid profiles dominated by $\mathrm{C}_{31} n$-alkanes are likely to 30 originate from $\mathrm{C}_{3}$ or $\mathrm{C}_{4}$ wild grasses or lake-margin plants, such 31 as sedges ${ }^{25-27}$. However, lipid profiles with typical $n$-alkane distri- 32 butions maximizing at $\mathrm{C}_{25}$ are highly unusual (Fig. 2a) and more 33 diagnostic to plant type. A predominance of $\mathrm{C}_{23}$ and $\mathrm{C}_{25} 34$ $n$-alkanes is known to be characteristic of submerged and floating 35 aquatic plants ${ }^{18,27}$, such as Potamogeton ${ }^{28}$, also found in the 36 pollen records in the region ${ }^{29}$. Calculation of the previously pro- 37 posed $P_{\text {aq }}$ proxy ratio further confirmed the lipid profiles with $\mathrm{C}_{25} 38$ $n$-alkane maxima likely to originate from aquatic plants (Table 139 and Supplementary information Table 1), with $P_{\text {aq }}$ ratio values 40 between 0.4 and 1.0 indicative of submerged or floating macro- 41 phytes at both sites. It is especially significant that continuity is 42 evident in the processing of aquatic plants in pottery spanning the 43 Early to Middle Holocene, which includes the transition from 44 hunter-gathering to pastoralism.

The extremely broad range of $\delta^{13} \mathrm{C}$ values for both the alkanoic 46 acids and $n$-alkanes confirms mixtures of $\mathrm{C}_{3}$ and $\mathrm{C}_{4}$ plants were 47 being processed in the vessels (Fig. $3 \mathrm{a}, \mathrm{b}$ and Supplementary 48 Information Table 1). The individual $\delta^{13} \mathrm{C}$ values for the leaf wax 49 $n$-alkanes from both sites range from -30.0 to $-17.7 \%$ for the 50 $\mathrm{C}_{25} n$-alkane, from -32.6 to $-23.1 \%$ or the $\mathrm{C}_{31} n$-alkane and 51 from -27.4 to $-13.8 \%$ for the $\mathrm{C}_{16: 0}$ fatty acid. These ranges reflect 52 the known $\delta^{13} \mathrm{C}$ values for both bulk plant lipids (from -32 to 53 $-20 \%$ o for $\mathrm{C}_{3}$ plants and from -17 to $-9 \%$ o for $\mathrm{C}_{4}$ plants $^{30}$ ) and 54 for leaf wax lipids, which are more depleted in ${ }^{13} \mathrm{C}$ than the 55 biomass (between -39 and $-29 \%$ in $\mathrm{C}_{3}$ plants and -26 and 56 $-14 \%$ in $\mathrm{C}_{4}$ plants $^{31}$ ). These ranges also encompass the carbon 57 isotope values of freshwater aquatic plants, which commonly 58 display a $\mathrm{C}_{4}$-like signature ${ }^{32}$ but, as discussed above, are separable 59 based on their respective $n$-alkane distributions.

Hence, the biomarker and stable isotope evidence from the 61 pottery are entirely consistent with the archaeobotanical record, 62 which comprises plants commonly found in the savannah and 63 freshwater habitats present in the Holocene green Sahara 64 (Supplementary Information Fig. 6). What is especially significant 65 is that this is the first evidence that these plants were being processed 66 in pottery vessels at least 10,000 years ago, with a prevalence of plant 67 over animal lipid residues (54\% of the total residues recovered from 68 the vessels have a predominantly plant source, with the remainder 69 comprising animal fats or mixtures of plant and animal products) 70 in the pottery assemblages, emphasizing the importance of a wide 71 
Table 1 | P/S ratios, CPI, ACL, weighted mean, $P_{\text {aq }}$ values and classifications of trimethylsilylated total lipid extracts from Takarkori rock shelter and Uan Afuda cave.

\begin{tabular}{|c|c|c|c|c|c|c|c|}
\hline Sample no. & Archaeological phase & $\mathrm{P} / \mathrm{S}$ ratio & $\mathrm{CPI} \mathrm{C}_{23}-\mathrm{C}_{33}$ & $\mathrm{ACL} \mathrm{C}_{23}-\mathrm{C}_{33}$ & Weighted mean $\delta^{13} \mathrm{C}$ & $P_{\text {aq }}$ & Classification \\
\hline TAK4 & Late Acacus & 3.1 & 2.1 & 27.7 & -23.2 & 0.55 & Aquatic plant \\
\hline TAK14 & Middle Pastoral & 2.0 & $n / d$ & 28.9 & -29.2 & $\mathrm{n} / \mathrm{d}$ & $\mathrm{C}_{3}$ grass \\
\hline TAK23 & Late Acacus & 2.6 & 5.7 & 28.7 & -21.4 & $n / d$ & $\mathrm{C}_{4}$ grass or aquatic \\
\hline TAK24 & Early Pastoral & 5.4 & $n / d$ & 28.5 & -22.4 & $n / d$ & $\mathrm{C}_{4}$ grass or aquatic \\
\hline TAK82 & Middle Pastoral & 2.8 & 8.1 & 28.5 & -21.2 & $n / d$ & $\mathrm{C}_{4}$ grass or aquatic \\
\hline TAK135 & Middle Pastoral & 5.0 & $n / d$ & 28.2 & -23.3 & 0.55 & Aquatic plant \\
\hline TAK159 & Middle Pastoral & 4.2 & $n / d$ & 27.4 & -20.7 & 0.61 & Aquatic plant \\
\hline TAK479 & Middle Pastoral & 4.6 & 5.2 & 27.7 & -27.2 & 0.58 & Aquatic plant \\
\hline TAK709 & Middle Pastoral & 2.5 & 3.9 & 29.4 & $n / d$ & $n / d$ & $\mathrm{C}_{4}$ grass \\
\hline TAK730 & Middle Pastoral & 4.8 & 5.1 & 28.9 & -25.0 & $\mathrm{n} / \mathrm{d}$ & $\mathrm{C}_{3}$ grass \\
\hline TAK766 & Middle Pastoral & 2.9 & 8.1 & 26.3 & -19.5 & 0.80 & Aquatic plant \\
\hline TAK860 & Middle Pastoral & 4.0 & $n / d$ & 28.6 & -21.4 & $n / d$ & $\mathrm{C}_{4}$ grass or aquatic \\
\hline TAK873 & Middle Pastoral & 2.0 & 4.6 & 29.5 & -22.4 & $n / d$ & $\mathrm{C}_{4}$ grass/sedge \\
\hline TAK953 & Middle Pastoral & 2.1 & 7.6 & 28.9 & -24.0 & 0.35 & $\mathrm{C}_{4}$ grass/sedge \\
\hline TAK1008 & Middle Pastoral & 2.5 & $n / d$ & 27.9 & -26.3 & $\mathrm{n} / \mathrm{d}$ & Aquatic plant? \\
\hline TAK1054 & Middle Pastoral & 3.1 & $n / d$ & 28.4 & -23.9 & 0.58 & Aquatic plant \\
\hline TAK1072 & Middle Pastoral & 2.9 & $n / d$ & 28.1 & -20.7 & 0.57 & Aquatic plant \\
\hline TAK1531 & Middle Pastoral & 4.0 & $\mathrm{n} / \mathrm{d}$ & 28.4 & -24.9 & $\mathrm{n} / \mathrm{d}$ & Aquatic plant? \\
\hline UAF A1 & Late Acacus & 3.7 & $n / d$ & 29.2 & -24.9 & $n / d$ & $\mathrm{C}_{3}$ plant \\
\hline UAFA3 & Late Acacus & 3.7 & $n / d$ & 27.3 & $n / d$ & 0.89 & Aquatic plant \\
\hline UAF20 & Late Acacus & 1.5 & $n / d$ & 28.7 & -21.5 & $\mathrm{n} / \mathrm{d}$ & $\mathrm{C}_{3}$ plant \\
\hline UAF45 & Late Acacus & 4.7 & $n / d$ & 26.0 & $n / d$ & 0.75 & Aquatic plant \\
\hline UAF46 & Late Acacus & 4.7 & $n / d$ & 27.7 & -26.4 & $n / d$ & Aquatic plant? \\
\hline UAF50 & Late Acacus & 4.2 & $n / d$ & 26.3 & $n / d$ & $n / d$ & Aquatic plant? \\
\hline UAF84 & Late Acacus & 14.3 & $n / d$ & 26.9 & $n / d$ & $n / d$ & Aquatic plant? \\
\hline
\end{tabular}

Late Acacus period 8,900-7,400 years uncalibrated years BP, 8,300-6,100 calBc. Early Pastoral 7,400-6,400 years uncalibrated years BP, 6,300-5,300 calBc. Middle Pastoral 6,100-5,000 years uncalibrated years $B P, 5,200-3,900$ calBc $12,13 . n / d$, not determined, signal intensity too low; $P / S$ ratio, relative abundance ratio $C_{16} / C_{18}$ fatty acids values greater than 4 indicate a plant origin; $C P I$, measures the relative abundance of odd over even carbon chain lengths, for example CPI values for all plant species have strong odd-chain preferences, with $\mathrm{CPI}$ values varying between 1.6 and $82.1^{17}$. ACL, weight-averaged number of carbon atoms of the higher plant $C_{25}-C_{33} n$-alkanes ${ }^{16} ; P_{a q}$ emergent and non-emergent aquatic macrophyte input; $P_{\text {aq }}<0.1$ corresponds to a terrestrial plant input; $P_{\text {aq }} 0.1-0.4$ to emergent macrophytes; and $P_{\text {aq }}$ 0.4-1.0 to submerged or floating macrophytes ${ }^{18}$.

1 variety of plants, including grains/seeds, leafy and aquatic plants in 2 the diet of these prehistoric people. Significantly, although the archaeobotanical record across North African sites suggests the
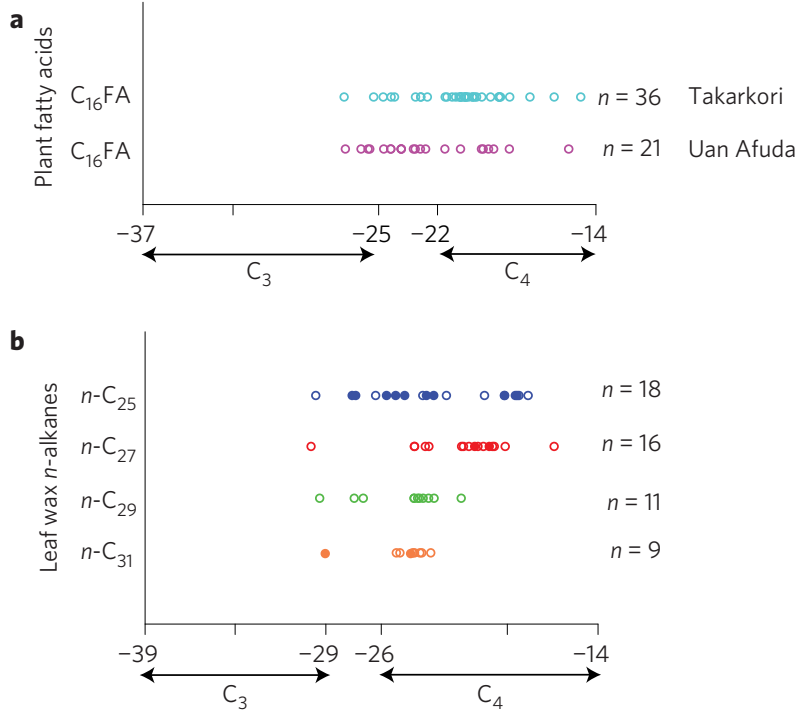

Figure 3 | Plot showing range of $\delta^{13} \mathrm{C}$ values for the alkanoic acids and $n$-alkane lipids derived from absorbed residues preserved in pottery from the Uan Afuda cave and Takarkori rockshelter, Libyan Sahara. These $\delta^{13} \mathrm{C}$ values confirm a combination of $C_{3}$ and $C_{4}$ plants were being processed in the vessels. The ranges reflect the known $\delta^{13} \mathrm{C}$ values for both bulk plant lipids (from -32 to $-20 \%$ and from -17 to $-9 \%$ for $\mathrm{C}_{4}$ plants ${ }^{30}$ ) and for leaf wax lipids that are more depleted in ${ }^{13} \mathrm{C}$ than the biomass (between -39 and $-29 \%$ in $C_{3}$ plants and -26 and $-14 \%$ in $C_{4}$ plants ${ }^{31}$ ). FA, fatty acid. consumption of plantstuffs such as cereals (seeds) and sedges, confirmed by these data, the role of aquatic plants in the diets of these prehistoric groups was not previously known. This exploitation of such a variety of plants highlights the sophistication of these early hunter-gatherer groups. Specific examples of where the pottery lipid and archaeobotanical records converge include (1) evidence for different parts of Typha or cattail, found at Takarkori 10 (Fig. 1a) and Uan Afuda, including rhizomes, peeled stems, flower 11 spikes and pollen, which are known to have been exploited as a 12 food source across the world ${ }^{6,33}$, and (2) consumption of leaves, 13 stems and starchy edible rhizomes of some Potamogeton ${ }^{34}$. 14 Processing of this type of emergent flora has a long history of use 15 in North Africa ${ }^{35}$, based on finds of carbonized rhizomes of 16 several sedges (Cyperus rotundus, Scirpus maritimus and S. tubero- 17 sus) at Wadi Kubbaniya, Egypt, c. 17,000-15,000 BC. Grindstones, 18 ubiquitous in North African archaeological deposits, and abundant 19 in the archaeological layers at Uan Afuda and Takarkori, would have 20 facilitated the processing of these wild plants.

In summary, these findings provide unequivocal evidence for 22 extensive early processing of plant products in pottery vessels, likely 23 to have been invented in this region for this purpose ${ }^{10,36}$. The 24 higher frequency of plant product processing than animal products 25 is unique in prehistoric pottery assemblages. From a temporal per- 26 spective the results indicate prolonged processing of a broad range 27 of plant material within vessels, dating from the Early Holocene. 28 This is contemporaneous with the introduction of pottery in the 29 region and continued for more than 4,000 years. Viewed together, 30 this highlights the sophistication of both food procurement strategies 31 and processing techniques of early Holocene North African foragers, 32 having important implications for dietary security in the changing 33 environments of the green Sahara. Ultimately, the adoption of these 34 broad resource economies, together with a 'package' of ceramic con- 35 tainers, stone tools, grinding equipment and storage facilities, were 36 the cultural prerequisites for the rapid adoption of domesticated 37 
animals in North Africa. Interestingly, these data demonstrate that plant processing maintains its importance in the subsistence strategies of these prehistoric groups, occurring both contemporaneously with, and following, the adoption of domesticates and the exploitation of secondary products?

Significantly, African plant domestication did not occur until much later, around 2,500 BC, likely to be in part because the midHolocene savannah provided sufficient wild-growing grains and other plants to meet the people's dietary needs. Finally, adoption of these new plant-processing techniques, using thermally resistant ceramic cooking vessels, would also have had far-reaching implications for improvements in human nutrition, health and energy gain. Critically, significant evolutionary advantages would have accrued through the provision of cooked foods, soft enough to be palatable for infants, potentially leading to earlier weaning and shorter interbirth intervals, thereby enhancing the fertility of women in early pastoral communities.

\section{Methods}

Lipid analysis and interpretations were performed using established protocols described in detail in earlier publications $s^{4,9}$. All solvents used were HPLC grade (Rathburn) and the reagents were analytical grade (typically $>98 \%$ of purity). Briefly, $\sim 2 \mathrm{~g}$ of potsherd were sampled and surfaces cleaned with a modelling drill to remove any exogenous lipids. The sherds were then ground to a powder, an internal standard added to enable quantification of the lipid extract ( $n$-tetratriacontane, typically $40 \mu \mathrm{g}$ ) and solvent extracted by ultrasonication (chloroform/methanol, 2:1 $v / v, 2 \times 10 \mathrm{ml}$ ). The solvent was evaporated under a gentle stream of nitrogen to obtain the TLE. Aliquots of the TLE were trimethylsilylated (, $\mathrm{O}$-bis(trimethylsilyl) trifluoroacetamide, Sigma Aldrich, $80 \mu \mathrm{l}, 70^{\circ} \mathrm{C}, 1 \mathrm{~h}$ ) and then analysed by hightemperature gas chromatography (HTGC) and GCMS to identify the major compounds present. All TLEs were initially screened in a Agilent Industries 7,890A GC system equipped with a fused-silica capillary column $(15 \mathrm{~m} \times 0.32 \mathrm{~mm})$ coated with dimethyl polysiloxane stationary phase (DB-1HT; film thickness, $0.1 \mu \mathrm{m}$ Agilent Technologies). Derivatized extracts $(1.0 \mu \mathrm{l})$ were injected on-column using a cool on-column inlet in track oven mode. The temperature was held isothermally for $2 \mathrm{~min}$ at $50^{\circ} \mathrm{C}$ and then increased at a rate of $10^{\circ} \mathrm{C} \mathrm{min}^{-1}$ and held at $350^{\circ} \mathrm{C}$ for $5 \mathrm{~min}$. The flame ionization detector (FID) was set at a temperature of $350^{\circ} \mathrm{C}$ Helium was used as a carrier gas, set to a constant flow $\left(4.6 \mathrm{ml} \mathrm{min}^{-1}\right)$. Dat acquisition and processing were carried out using the HP Chemstation software (Rev. B.03.02 (341), Agilent Technologies).

GCMS analyses of trimethylsilylated aliquots were performed using a ThermoFinnigan TraceMS operating at $70 \mathrm{eV}$ with a scanning range of 60-600 daltons. Samples were introduced by on-column injection. The analytical column $(15 \mathrm{~m} \times 0.32 \mathrm{~mm}$ ) was coated with dimethyl polysiloxane (ZB-1; film thickness, $0.12 \mu \mathrm{m})$. The temperature programming was from 50 to $300^{\circ} \mathrm{C}$ at $10^{\circ} \mathrm{C} \mathrm{min}{ }^{-1}$, following a $2 \mathrm{~min}$ isothermal hold at $50^{\circ} \mathrm{C}$. At the end of the temperature programming the $\mathrm{GC}$ oven was kept at $300^{\circ} \mathrm{C}$ for $10 \mathrm{~min}$. Helium was used as the carrier gas. Data acquisition and processing were carried out using XCalibur software (version 2.0.6). Peaks were identified on the basis of their mass spectra and GC retention times, by comparison with the NIST mass spectral library (version 2.0).

Further aliquots of the TLE were treated with $\mathrm{NaOH} / \mathrm{H}_{2} \mathrm{O}(9: 1 w / v)$ in methanol $\left(5 \% v / v, 70^{\circ} \mathrm{C}, 1 \mathrm{~h}\right)$. Following neutralization, lipids were extracted into chloroform and the excess solvent evaporated under a gentle stream of nitrogen. Fatty acid methyl esters (FAMEs) were prepared by reaction with $\mathrm{BF}_{3}$-methanol $(14 \% w / v$ Sigma Aldrich, $70^{\circ} \mathrm{C}, 1 \mathrm{~h}$ ). The FAMEs were extracted with chloroform and the solvent removed under nitrogen. The FAMEs were redissolved into hexane for analysis by GC-C-IRMS.

The majority of carbon isotope analyses were carried out by GC-C-IRMS using an Agilent 6,890 GC gas chromatograph, with a CTC A200S autosampler coupled to a Finnegan MAT Delta ${ }^{\text {plus }}$ XL mass spectrometer using a Finnigan MAT GCCIII interface. Samples were injected by means of a PTV injector in splitless mode, with a temperature increasing from 70 to $300^{\circ} \mathrm{C}$. The GC was fitted with a Varian fused silica capillary column (CP-Sil5CB, 100\%

dimethylpolysiloxane with $0.12 \mu \mathrm{m}$ film thickness, $50 \mathrm{~m} \times 0.32$ i.d.). Helium was used as the carrier gas at a flow rate set at $2 \mathrm{ml} \mathrm{min}^{-1}$. Copper, nickel and platinum $(0.1 \mathrm{~mm})$ were used in the alumina combustion reactor $(0.5 \mathrm{~mm}$ i.d.). The combustion reactor temperature was maintained at $950^{\circ} \mathrm{C}$. The temperature programme comprised a $2 \mathrm{~min}$ isothermal period at $50^{\circ} \mathrm{C}$ increasing to $250^{\circ} \mathrm{C}$ at a rate of $10^{\circ} \mathrm{C} \mathrm{min}^{-1}$, followed by an isothermal period of $15 \mathrm{~min}$ at $250{ }^{\circ} \mathrm{C}$ Faraday cups were used to select ions of $m / z 44\left({ }^{12} \mathrm{C}^{16} \mathrm{O}_{2}\right), \mathrm{m} / z 45\left({ }^{13} \mathrm{C}^{16} \mathrm{O}_{2}\right.$ and $\left.{ }^{12} \mathrm{C}^{17} \mathrm{O}^{16} \mathrm{O}\right)$ and $\mathrm{m} / \mathrm{z} 46\left({ }^{12} \mathrm{C}^{18} \mathrm{O}^{16} \mathrm{O}\right)$

Received 6 July 2016; accepted 10 November 2016; published XX XX 2016

\section{References}

1. Wrangham, R. W., Holland Jones, J., Laden, G., Pilbeam, D. \& Conklin-Brittain, $\mathrm{N}$. The raw and the stolen: cooking and the ecology of human origins. Curr. Anth. 40, 567-594 (1999).

2. Carmody, R. N. \& Wrangham, R. W. The energetic significance of cooking. J. Hum. Evol. 57, 379-391 (2009).

3. Sponheimer, M. et al. Isotopic evidence of early hominin diets. Proc. Natl Acad. 80 Sci. USA 110, 10513-10518 (2013).

4. Evershed, R. P. et al. Earliest date for milk use in the Near East and southeastern Europe linked to cattle herding. Nature 455, 528-531 (2008).

5. Wandsnider, L. The roasted and the boiled: food composition and heat treatment with special emphasis on pit-hearth cooking. J. Anth. Archaeol. 16, 1-48 (1997)

6. Mercuri, A. M. Plant exploitation and ethnopalynological evidence from the Wadi Teshuinat area (Tadrart Acacus, Libyan Sahara). J. Archaeol. Sci. 35, 1619-1642 (2008).

7. Zeder, M. A. The broad spectrum revolution at 40: resource diversity, intensification, and an alternative to optimal foraging explanations. J. Anth. Archaeol. 31, 241-264 (2012)

8. de Menocal, P. et al. Abrupt onset and termination of the African Humid Period: 92 rapid climate responses to gradual insolation forcing. Quat. Sci. Rev. 19, 347-361 (2000)

9. Dunne, J. et al. First dairying in green Saharan Africa in the fifth millennium BC. Nature 486, 390-394 (2012).

10. Huysecom, E. et al. The emergence of pottery in Africa during the tenth millennium cal BC: new evidence from Ounjougou (Mali). Antiquity 83, 905-917 (2009).

11. Jordan, P. et al. Modelling the diffusion of pottery technologies across Afro- 101 Eurasia: emerging insights and future research. Antiquity 90, 590-603 (2016). 102

12. di Lernia, S. (ed.) in The Uan Afuda Cave: Hunter-Gatherers Societies of Central 103 Sahara. Arid Zone Archaeology, Monographs 1. (All'Insegna del Giglio, 1999). 104

13. Biagetti, S. \& di Lernia, S. Holocene deposits of Saharan rock shelters: the case of 105 Takarkori and other sites from the Tadrart Acacus Mts. (southwest Libya). Afric. 106 Archaeol. Rev. 30, 305-328 (2013).

14. Castelletti, L., Castiglioni, E., Cottini, M. \& Rottoli, M. in The Uan Afuda Cave: 108 Hunter-Gatherer Societies of Central Sahara. Arid Zone Archaeology, 109 Monographs 1 (ed. di Lernia, S.) 131-148 (All'Insegna del Giglio, 1999). 110

15. Olmi, L. et al. in Windows on the African Past: Current approaches to African 111 Archaeobotany (eds Fahmy, A., Kahlheber, S. \& D’Andrea, A. C.) (Breitschuh \& 112 Kock, 2011).

16. Eglinton, G. \& Hamilton, R. J. Leaf epicuticular waxes. Science 156, $1322-1335$ (1967) \& Graham, H. V. Production of 116 $n$-alkyl lipids in living plants and implications for the geologic past. Geochim. 117 Cosmochim. Acta 75, 7472-7485 (2011).

18. Ficken, K. J., Li, B., Swain, D. L. \& Eglinton, G. An $n$-alkane proxy for the 11 sedimentary input of submerged/floating freshwater aquatic macrophytes. Org. 120 Geochem. 31, 745-749 (2000).

19. Mills, J. S. \& White, R. The Organic Chemistry of Museum Objects (Butterworth 122 and Co. Ltd, 1994).

20. Eckey, E. W. Vegetable Fats and Oils (Reinhold, 1954).

21. Hilditch, T. P. \& Williams, P. N. The Chemical Constitution of Natural Fats (Wiley, 1964)

22. Gurr, M. I. in Lipids: Structure and Function (ed. Stumpf, P. K.) 205-248 (Academic Press, 1980)

23. Romanus, K. et al. An evaluation of analytical and interpretative methodologies 129 for the extraction and identification of lipids associated with pottery sherds from 130 the site of Sagalassos. Turkey Archaeometry 49, 729-747 (2007).

24. Walton, T. J. in Methods in Plant Biochemistry Vol. 4 (eds Harwood, J. L and 132 Bowyer, J. R.) 105-158 (Academic Press, 1990).

25. Maffei, M. Chemotaxonomic significance of leaf wax alkanes in the Gramineae. 134 Biochem. System. and Ecol. 24, 53-64 (1996).

26. Rommerskirchen, F., Plader, A., Eglinton, G., Chikaraishi, Y. \& Rullkötter, J. Chemotaxonomic significance of distribution and stable carbon isotopic composition of long-chain alkanes and alkan-1-ols in $\mathrm{C}_{4}$ grass waxes. Org. Geochem. 37, 1303-1332 (2006).

27. Kolattukudy, P. E., Croteau, R. \& Buckner, J. S. in Chemistry and Biochemistry of 140 Natural Waxes (ed. Kolattukudy, P. E.) 289-347 (Elsevier, 1976).

28. Tuo, J., Wu, C., Zhang, M. \& Chen, R. Distribution and carbon isotope 142 composition of lipid biomarkers in Lake Erhai and Lake Gahai sediments on the 143 Tibetan plateau. J. Grt Lakes Res. 37, 447-455 (2011).

29. Cremaschi, M. et al. Takarkori rock shelter (SW Libya): an archive of Holocene 145 climate and environmental changes in the central Sahara. Quat. Sci. Rev. 101, 146 36-60 (2014).

30. Boutton, T. W. in Carbon Isotope Techniques (eds Coleman, D. C. \& Fry, B.) (Academic Press, 1991).

31. Bi, X., Sheng, G., Liu, X., Li, C. \& Fu, J. Molecular and carbon and hydrogen isotopic composition of $n$-alkanes in plant leaf waxes. Org. Geochem. 36, 1405-1417 (2005) ,

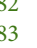
84 85 87

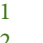
3 94 96 , 00 . ,

\section{(75.} 7 88 0 .

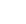


32. Keeley, J. E. \& Sandquist, D. R. Carbon: freshwater plants. Plant, Cell \& Environ. 15, 1021-1035 (1992)

33. Gott, B. Cumbungi, Typha species: a staple Aboriginal food in Southern Australia. Austr. Aboriginal Stud. 33-50 (1999).

34. Vizgirdas, R. \& Rey-Vizgirdas, E. Wild Plants of the Sierra Nevada (University of Nevada Press, Reno, 2006).

35. Hillman, G. C. in Foraging and Farming: the Evolution of Plant Exploitation (eds Harris, D. R. \& Hillman, G. C.) 207-239 (Unwin Hyman, 1989).

36. Haaland, R. Porridge and pot, bread and oven: food ways and symbolism in Africa and the Near East from the Neolithic to the present. Cambridge Arch. J. 17, 165-182 (2007).

\section{Acknowledgements}

We thank the UK Natural Environment Research Council for the Life Science Mass Spectrometry Facility (contract no. R8/H10/63; http://www.lsmsf.co.uk) and a PhD studentship to J.D (NE/1528242/1). We also thank H. Grant of the NERC Life Sciences

Mass Spectrometry Facility (Lancaster node) for stable isotopic characterisation of

reference standards and derivatizing agents. Sapienza University of Rome (Grandi Scavi di

Ateneo) and the Italian Minister of Foreign Affairs (DGSP) are thanked for funding for the

Italian Archaeological Mission in the Sahara to S.D.L. Libyan colleagues of the Department

of Archaeology in Tripoli and Ghat, in particular S. Agab, Tripoli, are also thanked. Two
PhD students, L. Olmi and R. Fornaciari, who studied the wild cereal archaeobotanical $\quad 21$ record, are also thanked. This study is dedicated to the memory of the remarkable scholar 22 Geoffrey Eglinton, FRS, who died in March 2016. The findings of this paper rest in 23 large part on the use of plant leaf wax biomarkers pioneered 50 years ago in Eglinton, 24 G. \& Hamilton, R.J. $(1967)^{16}$.

\section{Author contributions} R.P.E. and S.D.L. conceived and planned the project. J.D., R.P.E., S.D.L. and A.M.M. wrote 27 the paper. J.D. performed analytical work and data analysis. S.D.L. designed and directed 28 the excavations and field sampling; A.M.M. studied the archaeobotanical materials and S.B. 29 performed analytical work. All authors read and approved the final manuscript.

\section{Additional information}

Supplementary information is available for this paper. Reprints and permissions information 32 is available at www.nature.com/reprints. Correspondence and requests for materials should be 33 addressed to R.P.E.

\section{Competing interests}

The authors declare no competing financial interests. 
Journal: $\quad$ NPLANTS

Article ID: $\quad$ nplants.2016.194

Article Title: Earliest direct evidence of plant processing in prehistoric Saharan pottery

Author(s): Julie Dunne et al.

\begin{tabular}{|l|l|l|}
\hline Query no. & Queries & Response \\
\hline Q1 & Ref 12: please provide page range for the chapter & \\
\hline Q2 & Ref 15: please provide chapter page range & \\
\hline Q3 & Ref. 30: please provide chapter page range & \\
\hline
\end{tabular}

